\title{
Collaborative action for person-centred coordinated care (P3C): an approach to support the development of a comprehensive system-wide solution to fragmented care
}

Helen M. Lloyd ${ }^{1 *}$, Mark Pearson ${ }^{3,4}$, Rod Sheaff ${ }^{2}$, Sheena Asthana ${ }^{2}$, Hannah Wheat', Thava Priya Sugavanam?', Nicky Britten ${ }^{3,4}$, Jose Valderas ${ }^{3,4}$, Michael Bainbridge ${ }^{5}$, Louise Witts ${ }^{6}$, Debra Westlake ${ }^{1}$, Jane Horrell ${ }^{1}$ and Richard Byng ${ }^{1}$

\begin{abstract}
Background: Fragmented care results in poor outcomes for individuals with complexity of need. Person-centred coordinated care (P3C) is perceived to be a potential solution, but an absence of accessible evidence and the lack of a scalable 'blue print' mean that services are 'experimenting' with new models of care with little guidance and support. This paper presents an approach to the implementation of P3C using collaborative action, providing examples of early developments across this programme of work, the core aim of which is to accelerate the spread and adoption of P3C in United Kingdom primary care settings.

Methods: Two centrally funded United Kingdom organisations (South West Collaboration for Leadership in Applied Health Research and Care and South West Academic Health Science Network) are leading this initiative to narrow the gap between research and practice in this urgent area of improvement through a programme of service change, evaluation and research. Multi-stakeholder engagement and co-design are core to the approach. A whole system measurement framework combines outcomes of importance to patients, practitioners and health organisations. Iterative and multi-level feedback helps to shape service change while collecting practice-based data to generate implementation knowledge for the delivery of P3C. The role of the research team is proving vital to support informed change and challenge organisational practice. The bidirectional flow of knowledge and evidence relies on the transitional positioning of researchers and research organisations.

(Continued on next page)
\end{abstract}

\footnotetext{
*Correspondence: helen.lloyd-1@plymouth.ac.uk

${ }^{1}$ Community and Primary Care Research Group, Clinical Trails and Population

Studies, Peninsula School of Medicine and Dentistry, Room N14, ITTC

Building, Plymouth Science Park, Derriford, Plymouth, Devon PL6 8BX, United

Kingdom

Full list of author information is available at the end of the article
} 
(Continued from previous page)

Results: Extensive engagement and embedded researchers have led to strong collaborations across the region. Practice is beginning to show signs of change and data flow and exchange is taking place. However, working in this way is not without its challenges; progress has been slow in the development of a linked data set to allow us to assess impact innovations from a cost perspective. Trust is vital, takes time to establish and is dependent on the exchange of services and interactions. If collaborative action can foster P3C it will require sustained commitment from both research and practice. This approach is a radical departure from how policy, research and practice traditionally work, but one that we argue is now necessary to deal with the most complex health and social problems.

Keywords: Person-centred coordinated care, Collaborative action, Integration

\section{Background - the problem of fragmented health and social care}

Fragmented and poorly coordinated care are enduring problems for health and social care systems worldwide [1]. These problems impact most acutely on individuals with complex bio-psychosocial needs [2-8], older individuals considered as 'frail', and those with multiple long-term conditions [9-11]. Poor coordination occurs most often when care spans the health service and non-statutory and social care boundaries, but is not limited to those interfaces [12]. Within healthcare in England (e.g. general practice, community nursing, mental health services and acute hospitals), there is also a failure to ensure key clinical functions for the individual patient are delivered in a coordinated and person-centred manner. These include preventing and responding to urgent care needs, rational management of multiple long-term conditions (polypharmacy, self-care) and support to promote social health along with mental and physical wellbeing. Furthermore, the burden of care for these individuals is high [13-15] in emotional, practical and financial terms, and impacts upon practitioner morale and patient outcomes [16, 17]. This paper describes a comprehensive approach to address the enduring problems of non-person-centred and fragmented care, by uniting researchers, professionals, patients and a range of delivery organisations to collectively address this problem.

In the United Kingdom, three potent and interacting problems have contributed to the fragmentation of health and social care over the last 25 years. The first resides in the increasing specialisation of medicine and professional roles, and the second in governments' initiation of repeated, rapid cycles of service reorganisation, privatisation and contracting [18]. The third problem, and the one addressed through our programme of collaborative action, concerns the nature of the available evidence and the accessibility of it to inform service delivery improvements. This paper details an innovative approach to knowledge mobilisation that we are using which combines evidence from research, knowledge from practice, and information from routinely collected data to flow around and be used within complex health and social care systems.
Current evidence concerning how to implement integrated care is hard to use in a meaningful way because of its disparate nature and the mismatch between long research cycles and the needs of service redesign. In addition, confusion between different but related concepts such as integration, care coordination and continuity of care [19], add further challenges. For example, 'integrated care' is related to previous 'solutions', such as shared care, chronic disease management and collaborative care [20-22], and was for a period focussed in health and social care, but has now also been deflected for quite different purposes such as cost containment [23, 24] and the vertical integration of care (i.e. the coordination of acute and community services by a single provider or a linked set of providers) [19].

Policy-makers and commissioners perceive this allembracing concept of 'integration', with its focus on removing discontinuities in care, as the solution to fragmented care. The problem here is that 'integration' is a diverse concept with numerous definitions and a multitude of interacting dimensions and interdependencies across a system [25]. Such complexity is not easily nor simply translated into implementation models, and with context often ignored, efforts towards implementation are often hindered despite energised initiatives (cf. United Kingdom Integration Pilots and Pioneers) [26].

Drawing upon organisational theory and empirical research, Leutz [27] and Sheaff [3] avoid the temptation of giving the term 'integration' a moral loading, defining the integrated organisation of care as:

"A form of organisation that contains a wide range of services (above all, primary medical care) and by coordinating them attempts to produce the continuities of care (cross-sectional, longitudinal, flexible, relational, and informational) through pooling the funds and resources for the different areas of its work, enabling it to provide whichever services it judges the most suited to the patient and most economical overall, irrespective of the received division of labour and without concern for the internal distribution of costs." 
Correspondingly, networks of organisations could be described as 'integrated' to the extent that they resemble this description. Notwithstanding the above definition, a model or 'blue print' for integrated care has yet to be established in terms of the necessary core features. The policy literature, although high on aspirations, also fails to provide details about how to implement core changes [28-30]. Given the lack of coherent guidance, it is unsurprising that healthcare systems have failed to significantly reduce fragmentation [31-35] and improve outcomes for those with complex healthcare needs [16, 36, 37].

A further challenge for services attempting integrated initiatives is that many models have not been sufficiently and robustly tested, at least in the United Kingdom. This is partly a result of the fracture between general practice and community health services, which is built into the present architecture of the NHS. Indeed, it is one of the two big features that NHS structural 'reforms' have left practically untouched (the other being NHS funding through taxation). For example, while policy prompted reconfigurations of hospital and community trusts can be imposed by internal management processes, it is harder to bring together needs-rated social care with tax-based NHS care, and to integrate multiple general practices (small businesses) with NHS bureaucratic trusts. Recent National Health Service England policy, outlined in the General Practice Forward View [38] and the Five Year Forward View [39], aspires to unify services by linking such service divisions. However, within the current United Kingdom context of purchaser provider splits and cumbersome contractual frameworks, it is still hard to envisage where and how these bridges will be built. It is unsurprising, therefore, that the most recent experiments with 'integrated care' (e.g. Integrated Care Pioneers) in the United Kingdom have failed to meet expectations to address the problems faced by patients $[26,40]$.

The following sections describe an approach to knowledge mobilisation being tested in the south west of England to generate and share knowledge and evidence to support the implementation of a comprehensive model of person-centred coordinated care (P3C) [41].

\section{The generation of accessible and timely knowledge through collaborative action to support the implementation of P3C \\ General approach}

Health systems are responding actively to policy imperatives for 'integration' and person-centred care, but these efforts are commonly piecemeal, untested, unevaluated and carried out in isolation, often in response to local leaders or crises. In the United Kingdom, whole system redesign has also begun to gain traction and, with this, the recognition that 'culture' change towards more integrated or coordinated care, which is also person centred, requires support and energy spanning different organisational levels, i.e. from individual practitioner to multi-professional team to whole provider-organisation, commissioner (payers) and beyond [5, 42]. Without concurrent and rigorous formative evaluation [43], the learning from these innovations is often short lived or ignored. Furthermore, with little understanding of how the context influences implementation, opportunities to create a wealth of insight are often lost. Consequently, 'whole system' implementation knowledge is well timed and requires the appropriate melding of traditional approaches to research (e.g. large randomised controlled trials, etc.) with those that can flex and explore the role of context (e.g. quality improvement, realist evaluation, action research). In spite of this, there are few comprehensive programmes that aim to (1) support the implementation of evidence-informed practice (where it exists) and (2) develop practice-based evidence about what works.

We have set about bringing together a 'whole systems' realist evaluation [44] incorporating service redesign, implementation, education, evaluation and research. We are using co-designed 'Collaborative Action' [45] in the context of the South West Peninsula Collaboration for Applied Health Research and Care (SW CLAHRC). Our approach shares much with that of Glasgow et al.'s [46] 'Evidence Integration Triangle', namely, prioritising actionable feedback to practice, a participatory implementation process, the shared understanding by participants of key components, and practical and ongoing measurement within a multilevel context. We hope that this regionwide initiative of collaborative groups (researchers, commissioners, providers and practitioners) will continue to bring a clarity of purpose and continued use of our common evaluation framework. Through this supportive process we are putting $\mathrm{P} 3 \mathrm{C}$ into practice locally whilst also providing a receptive context to support more research, thus contributing to a coherent body of knowledge.

\section{Support for local initiatives: measurement, theory and learning from experiential and other evidence}

The Five Year Forward View developed by NHS England presents a radical vision of reformed and integrated public services working alongside communities, social networks and the voluntary sector to support people living with longterm conditions [39]. A number of national programmes with local initiatives (Integrated Personal Commissioning programme [47], Vanguards [48], Realising the Value [49]) aim to embed person- and community-centred approaches to deliver this vision. To support these local initiatives, we have developed a taxonomic framework for P3C [41, 50, 51], and tools to monitor and develop this at a practice level $[41,51]$. This framework has been developed from our multidimensional definition of $\mathrm{P} 3 \mathrm{C}$, which is presented in Table 1. 
Table 1 The extended South West Peninsula Collaboration for Applied Health Research and Care definition of person-centred coordinated care (P3C)

Person-centred care

Capabilities and resources of the person and their wider social context

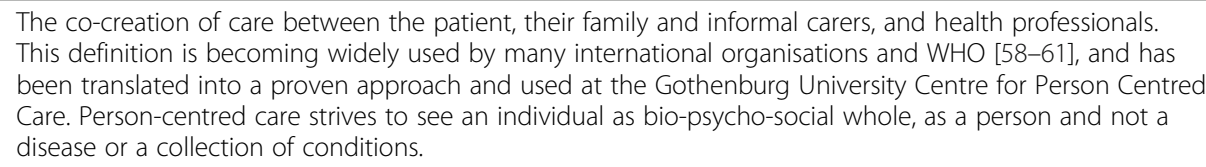

Psycho-social and environmental resources that are non-clinical and have a community focus. This is commonly being referred to as 'community-centred approaches' that complement other types of interventions that focus more on individual care and behaviour change, or on developing sustainable environments. These approaches acknowledge the importance of social capital for health and wellbeing to flourish, and acknowledging people as having capabilities and resources [62].

Care coordination is the deliberate combining, in the necessary forms and sequence, of patient care activities by three or more participants (including the patient) so as to deliver the healthcare chosen for the patient [63]. From a person or family perspective, care coordination is any co-operative activity that helps ensure that the individual's needs and preferences for health services are met, with effective information sharing across people, work-groups, organisations, and sites over time [63].
Using 'Collaborative Action' [45] and our evaluation framework, we are supporting the implementation of P3C. This involves expert practitioners, managers and researchers working together to help ensure progress in service provision by investigating how, where and why models work. This strategy presupposes that valuable knowledge can be derived from the evaluation of innovations. It also entails accepting that, while we can inform practice by what we do know (using evidence where we have it), we (researchers, practitioners, managers, patients and their carers) also acknowledge what we do not know, and are ready to try things out and create opportunities for experiential learning (including formalising already existing tacit or undocumented knowledge). This 'Collaborative Action' is depicted in Fig. 1 (where the arrows represent a flow and exchange of different types of knowledge or activities).

This collaborative approach facilitates the transfer and synthesis of different types of knowledge (i.e. published evidence and that developed from local practice) between specific local and wider national/international settings. Generating knowledge this way has the potential to make research more relevant to local ways of delivering care, i.e. by generating more practice-based evidence [52]. These strands are then synthesised and fed back into an emerging understanding of what $\mathrm{P} 3 \mathrm{C}$ is and how to support its implementation. This knowledge can also help develop an overarching causal framework (programme logic) to track how changes (e.g. team working, practitioner-patient interactions, etc.) occur and how they relate to improvements in outcomes (Fig. 2).

\section{A consistent evaluation framework for $\mathrm{P} 3 \mathrm{C}$}

Generating useful knowledge and improving practice models is facilitated by the use of a similar evaluation framework across settings. Based, therefore, on the changes anticipated in the overarching programme logic (Fig. 2), we are using a combination of co-selected metrics across core domains of interest (e.g. practitioner and patient experience [51, 53], patient activation [54], patient well-being [55], morbidity, mortality, cost and organisational processes [41]). Local services benefit from the results of the evaluation as these are used to shape the ongoing development of the model. We have found that supporting the development of specific evaluation frameworks for projects based on their objectives and targets improves quality, competency and ownership. Supporting health economies to develop the core measurements (e.g. cost of care, admission rates, experience of care, patient reported outcomes) and embed ways to collect data is helpful to monitor and understand the whole system. This will help create the knowledge that we need about how local care providers produce - or fail to - continuity of care for people with multiple chronic health problems. Crucially for P3C, this approach helps identify the mechanisms that explain how causal relationships occur (through the interaction of people's reasoning and the resources available to them) $[56,57]$.

Over the past 2 years, our collaborative effort has involved engagement and working with diverse local sites (Fig. 3) using a consistent multi-level and multiperspective evaluation framework (Fig. 4) for the evaluation of specific P3C innovations and system change. This framework reflects the complex interventions and organisational level changes that occur during P3C service reconfigurations. More importantly, however, it captures and uses the voice of patients and professionals to shape redesign efforts. For this purpose, we also collect multiperspective data at both individual and group level (Fig. 4).

This evaluation framework assesses if service change and developments are achieving pre-specified outcomes towards P3C. Using a three tiered and multi-perspective longitudinal mixed methods approach, the framework encompasses qualitative data, questionnaire data and service use and data (Fig. 4). Service use data capture 


\section{A collaborative programme for P3C}

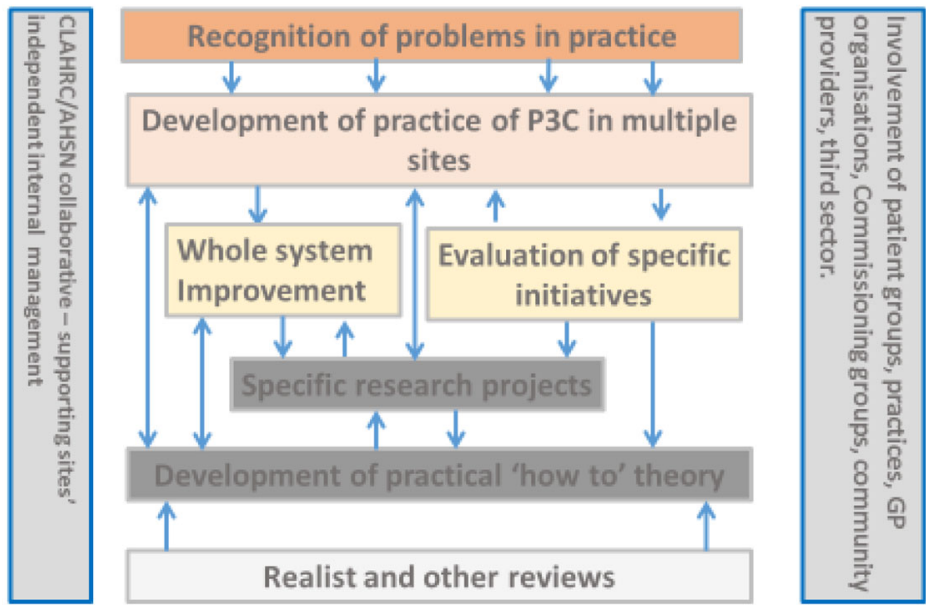

Fig. 1 Collective action: an alignment of resources for promoting and supporting person-centred coordinated care (P3C). Grey vertical pillars represent the positioning and type of organisations that are partners in the Collaborative effort. The light grey box and orange box depict the ways in which we come to know of the challenges and potential solutions to service redesign for P3C, and how we use this knowledge to inform practice and our emerging theory. The dark grey boxes and the beige box represent how, through specific projects and service development innovations, we are able to develop insights about what works and how we feed this back into practical efforts to support on-going development. The yellow boxes represent the scale of change, this could be a specific service or a system wide approach and how knowledge from these initiatives flows into the development of practice, the development of theory or defining specific research projects. The blue arrows represent the flow of knowledge around the system

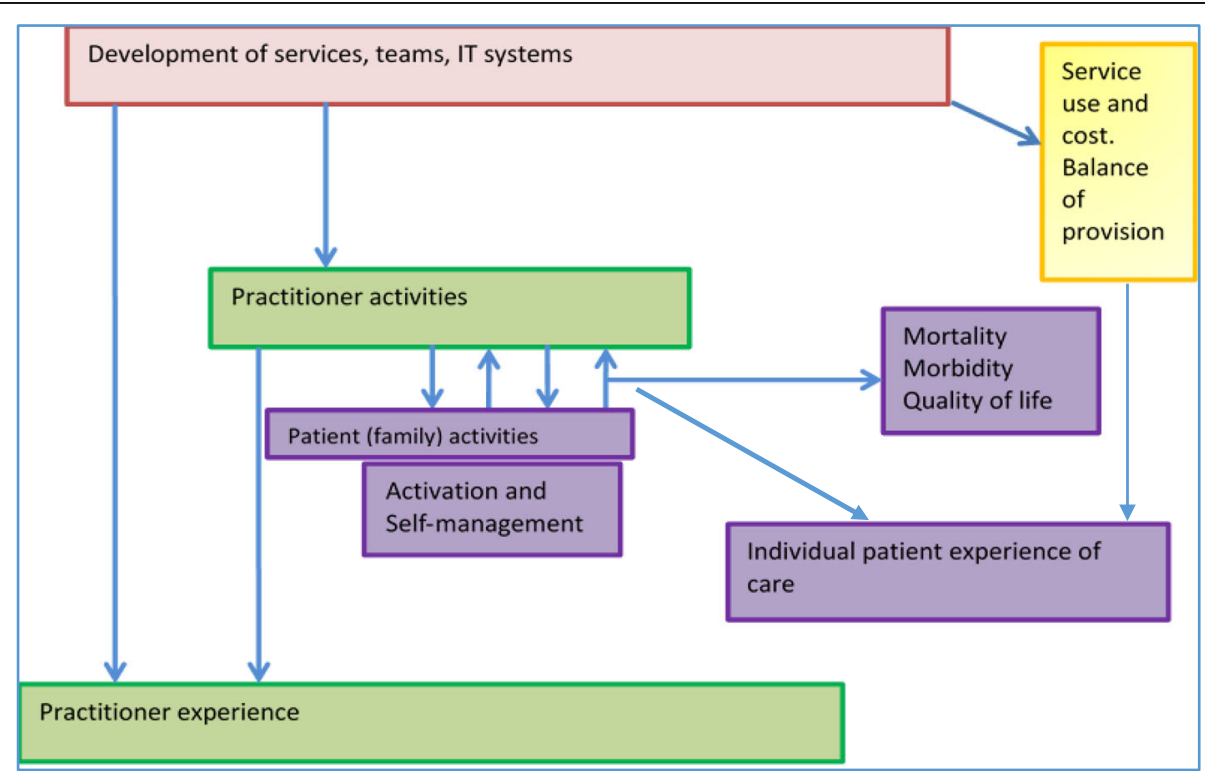

Fig. 2 Overarching logic model and evaluation domains for person-centred coordinated care across a system. Pink box represents the organisational changes and support that needs to take place with the arrow linking to the potential impact of this on how practitioners work with patients and how this impacts on their experiences of delivering care. The centre purple boxes represent patient and family/supporter activities and how these influence and are influenced by care interactions. The large blue arrows show how these activities have the potential to influence patient outcomes and experiences of care. The yellow box represent system outcomes and processes around cost and provision of care. These processes and outcomes are influenced by organisational processes (pink box) and, in turn, influence patient experiences of care 


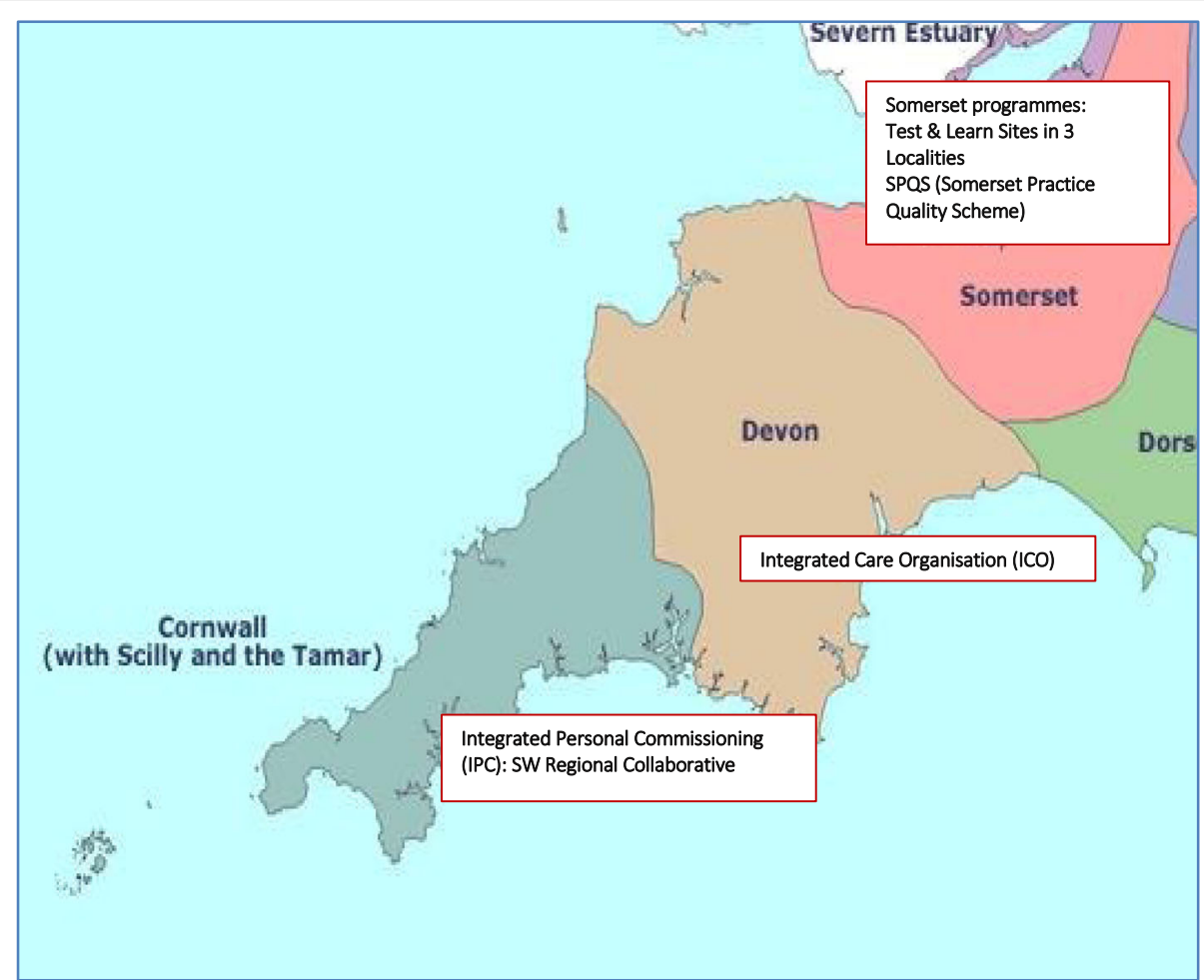

Fig. 3 South West United Kingdom practice-based evaluations of person-centred coordinated care. This figure depicts a map of the South West of England showing the counties and the sites with which the collaborative works

\section{P3C Evaluation Framework}
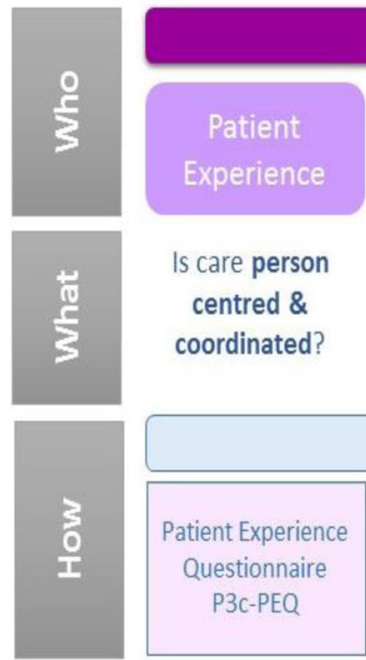

\section{Patient}

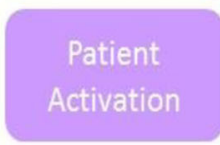

Is care person

centred \&

coordinated?

Is care improving

self management? and loneliness?

\section{Patient Health \\ \& Wellbeing}

Is care improving

Chenes?

(n)

Patient Experience

Questionnaire

P3C-PEQ

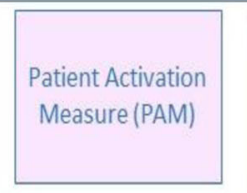

\section{Questionnaires}

Warwick Edinburgh

Wellbeing Scale

DeJong Loneliness

Scale

\section{Qualitative Interviews}

Fig. 4 Multi-perspective, multi-level measurement of change with specified measures. Purple boxes depict patient outcome domains, related questions and the measures used to gather this data. Similarly, the green boxes show the domains of interest aimed at practitioners. The red boxes depict the organisational process domains and the yellow boxes describe the cost activity outcomes to be measured. CSU clinical support unit 
allows for the assessment of patterns of service contact (GP attendance, hospital admissions, etc.) following exposure to an intervention with the intention to derive cost calculations. Staff experience data provides an insight into their perspective, whilst individual patients' perspectives are sought to assess if care has improved or worsened [51], and if there are any perceived improvements in health, wellbeing, loneliness and self-management. We have included loneliness and self-management as measurement dimensions as these were hypothesised as important to the target population of older people at risk of isolation with long-term conditions. This framework is being used in the English counties of Somerset and Devon (Fig. 3) and was co-designed with local system commissioners and providers in each of the three Clinical Commissioning Groups. This is being used both to monitor the system as a whole over time, and to evaluate particular initiatives and innovations. Generalisable knowledge is derived firstly through reviewing literature, using realist synthesis where feasible, and by comparison of data across the evaluation sites focusing on practitioner-patient interaction and organisational processes. We are also examining the process of implementation, both through the lens of existing knowledge about changing practice and quality improvement in the NHS, and also identifying specific organisational constraints and facilitators for developing system-wide P3C.

\section{Progress so far}

Over the past 2.5 years, extensive efforts have been made to foster partnerships between researchers and health and social care organisations at various levels. This has involved researchers adopting an 'embedded' style of engagement to gain insider knowledge of organisational systems and to build trust. Researchers have spent time attending management meetings, strategic board meetings and training sessions across a variety of provider organisations ranging from clinical commissioning groups, hospital trusts, mixed stakeholder groups forming integration boards, social care and voluntary sector organisations. Co-design workshops have taken place to create evaluation and development strategies for service innovations. In one site, we have two researchers in residence who have been funded by the Torbay Medical Research Fund to investigate the ongoing process of integrating different services. In another site, a system-wide longitudinal formative evaluation has provided a rich picture of how services have developed P3C applying differential system leavers to support this process. Both sites have benefited from regular feedback to chart the development of the system and demonstrate where processes and outcomes are improving.

Figure 3 displays the geographical spread of the settings we are working with across the south west of

Table 2 Examples of the service model innovations and organisational links

\begin{tabular}{|c|c|c|}
\hline Name of service model & Description of service model & Links established as a result of the collaboration \\
\hline $\begin{array}{l}\text { Somerset Test } \\
\text { and Learn }\end{array}$ & $\begin{array}{l}\text { Roll out of the Symphony Complex Care model, } \\
\text { developed in South Somerset, to other localities } \\
\text { (Taunton and Mendips) across Somerset. Variations } \\
\text { of linkage (networks) between primary, secondary } \\
\text { and voluntary sector organisations. }\end{array}$ & $\begin{array}{l}\text { South West Academic Health Science Network, } \\
\text { Department of Community and Primary Care Research } \\
\text { Group, Plymouth University, Health Connections Mendip } \\
\text { (NGO), Village Agents (NGO), University of York, general } \\
\text { practices across Somerset, Yeovil district hospital, } \\
\text { Musgrove Park hospital, South West clinical support unit, } \\
\text { Somerset County Council and Frome community hospital. }\end{array}$ \\
\hline $\begin{array}{l}\text { Somerset Practice } \\
\text { Quality Scheme }\end{array}$ & $\begin{array}{l}\text { General practitioners applying a 'system lever' } \\
\text { (discretion from pay for performance schemes) } \\
\text { to enable the development of the above innovations }\end{array}$ & $\begin{array}{l}\text { South West Academic Health Science Network, } \\
\text { Department of Community and Primary Care Research } \\
\text { Group, Plymouth University, } 55 \text { general practices in } \\
\text { Somerset, Somerset Clinical Commissioning Group, } \\
\text { Somerset County Council, Somerset Partnership Trust and } \\
\text { National Health Service England. }\end{array}$ \\
\hline
\end{tabular}

Torbay The integration of acute and community services across

Integrated Care Organisation five localities in South Devon. A range of around 30 service innovations and enabling functions are being rolled out in the new care model programme, including the deployment of Third Sector 'Well-being Coordinators', enhanced intermediate care, and multi-disciplinary health and well-being teams in locality hubs with primary care input

Integrated Personal Commissioning
Two demonstrator sites (Torbay and Cornwall) implementing a form of integrated personal budget that links services to personalised goals via a budget allocation. A range of statutory and non-statutory services are bro kered to achieve a coordinated and personalised plan based on the preferences of the individual patient.
South Devon Trust, Clinical Commissioning Group, Devon North East West Clinical Commissioning Group, Devon Partnership Trust, Torbay Council, Devon County Council, Healthwatch Torbay, Healthwatch Devon, Torbay Community Development Trust, Teignbridge Community and Voluntary Services, Volunteering in Health/Totnes Caring, Age UK Torbay, GP practices in Coastal Locality, South West Academic Health Science Network, Department of Community and Primary Care Research Group, Plymouth University and Oxford University.

NHSE national team, South West Academic Health Science Network, Department of Community and Primary Care Research Group, Plymouth University, Torbay Carers, Torbay Community Development Trust, Kernow Clinical Commissioning Group, Age UK, Devon North East West Clinical Commissioning Group and Torbay Council. 
England and Table 2 describes these settings, their models and the links that have been established or strengthened as a consequence of the collaboration.
The following two brief vignettes provide a more detailed snapshot of two of these service change models that we have been working with (Figs. 5 and 6).

Somerset is a rural county in the South West of England with a population of 549,447 recorded at the last census. The annual growth rate of the proportion of people between the ages of $65-74$ is an estimated 3.5\%; this is 5 times the national average. In response to the demands of an aging population with increasing numbers of long term conditions, Somerset health and social care providers embarked on an ambitious roll out of a model matured in the south of the county that targets older people with long term conditions.

The roll out of the Symphony programme works on a hub based model linking a networks services across health and social care in the North East (Frome and Mendip) and the West of the county (Taunton). The collective name for the three sites 'Test and Learn Somerset', reflects a forward thinking recognition of the cycles of iterative learning and development required for the implementation of complex innovations. The overarching aims of the hubs were to develop Person Centred Co-ordinated Care (P3C), achieve better outcomes for patients, and improve efficiency. South Somerset, the original home of the Symphony project, began operating out of Yeovil district hospital with links to participating general practices. Input from the hospital older person's service at the hospital was key to managing the most complex older people and their transitions into and out of hospital using a multi-morbidity model of care. The Taunton based site operated a virtual hub achieved through a Joint venture of providers (hospital, general practice, social care) who share resource and risk with an integrated P3C care team, focusing on people with 3+ long term conditions. Mendip (Frome) began from a general practice, hospital and strong voluntary sector alliance, co-located with health connectors (voluntary service professionals) to support people with 1+ long term condition who are house bound.

The three test and learn sites share many common elements despite variances in organisational arrangements and localised operationalisation of the model, these include:

- $\quad$ Single personalised care plan created from a comprehensive assessment with patient access

- A united patient pathway with expert generalist input

- Interdisciplinary working and multi-disciplinary team input

- Care coordinator (managing transitions)

- Professionals working in new roles to coach, coordinate or support patients (keyworkers, care coordinator, health connectors, wellbeing advisors)

- Access to pharmacy expertise

- Use of new technologies

- Extended role for voluntary sector

- SPoA (Single point of access)

- Rapid crisis response and escalation plans

- Admission and discharge planning

- Support and coaching for patients to work towards self-management using the Patient Activation Measure

Our evaluation of the Test and Learn programme is currently in its second year and over the course of this time we have regularly observed practice, collected data and fed this back to front line delivery staff, managers and commissioners. We have learnt that services can quickly test, learn and adapt delivery, to respond to patients in a more efficient, person-centred way. This has led to improved experiences of care and patient outcomes in some localities. We also found however that positive impact on patients' experiences, has been shown to be only immediate and short-term at sites where, at the time of data collection, there was an inadequate follow up system in place to maintain contact with patients. This was related to the over reliance on patients contacting the service at times of need, or a lack of capacity to both take on new cases and follow up on existing ones. This is an important paradox for models that are seeking to improve self-management in patients that may not be capable of this or be aware that this is expected of them, or where adequate self-management support is not in place. From the perspective of the patient we learnt that they highly valued the opportunity to engage in extended, holistic dialogue, continuity of care and having a single point of access with staff in new roles that the new model had created. These roles fostered a new form of patient-staff interactions and appeared to improve coordination; bridging the gap between the patient and their wider health care team. However, certain other activities relating to personalised care such as goal setting and co-developing care plans were less well received and engaged with by patients. 
The IPC programme started in April 2015 as a partnership between National Health Service England (NHSE) and the Local Government Association. IPC was seen as a way to extend the developing national personalisation agenda by building on and integrating existing health and social service personal budget programmes. Key to the IPC intervention is a focus on a 'different conversation', establishing 'what matters to you, rather than what is the matter with you', and the development of a shared care plan that may include a budget to be spent in ways that make sense to the individual. The South West was one of the first 9 demonstrator sites enlisted to develop the programme. The sites that we worked with to evaluate and support the development of the model were situated in Devon and Cornwall. Co-production of research and the implementation process via observation and iterative feedback were important.

IPC in the South West has enabled practitioners working with people with long term conditions, to work in partnership with them to identify 'what matters to them' and have a small budget to meet some of their health objectives. People who most benefited were people who typically had conditions that are fluctuating or hard to identify and experience chronic pain, limited mobility and associated mental health problems, but who 'fall through the gaps of services'. Key to positive outcomes for this group was the type of conversation with practitioners that looked beyond service-led goal setting and defined wider choices that can be funded directly by a budget, or indirectly via signposting. Participants experienced reduction in pain and increase in mobility. A peer support group at one site, was also critical to participants' positive outcomes in increased sense of wellbeing and reduction in social isolation, as was an ongoing relationship with a practitioner who made them 'feel heard'. The voluntary sector was central to providing community solutions and also to the maintenance of ongoing support to participants.

Lack of clarity from the national team about the key elements of the programme led to mismatched expectations on the ground. While participants saw the budget as a critical element of the intervention, used to fund resources such as complementary therapies, social activities or exercise solutions, practitioners and managers believed the budget was only one of a range of options that included existing community and statutory provision and self-management and, in reality, a health budget was the source of funding for only $40 \%-50 \%$ of the goals defined in the care planning process. This led to a lack of shared agreement between practitioners and participants about what constituted a 'goal' and an 'outcome' and participants did not always feel ownership of the care planning process. Both participants and practitioners were frustrated by delays in finance departments releasing funds and by a lack of transparency in budget allocation decisions. This part of the process did not feel person-centred to patients.

Fig. 6 Local Implementation of Integrated Personal Commissioning (IPC) in the South West

While evaluation is, of course, crucial to establish what works well and what not so well within these new models of care, it is important to remember that these new models are attempting to change not only processes, but also practitioner and patient mindsets, within workplaces with highly ingrained cultures. Such changes take a substantial amount of time to embed. In addition, while it is important for models to learn and evolve, continued communication and some aspect of continuity is essential for service teams and patients if they are to feel engaged, important and part of a service.

\section{Discussion}

Our experience, so far, has been positive; services want support and engagement and to create an evidence base for monitoring and reflecting on what changes they make.
There have been challenges, and the pressure services are under, in the form of policy drivers and the high turnover of senior managers and frontline staff, are also barriers for us to overcome. However, sustained engagement from commissioners and a range of providers has helped to reduce the impact that these barriers have imposed upon our evaluations and the services being delivered. The collaboration between the southwest Academic Health Science Network and the SW CLAHRC has also been instrumental in supporting engagement and ensuring robust evaluation. This is due to the active and trusted links that both organisations have with commissioning and service delivery organisations across the region and a strategic commitment to work in partnership with the local health and social care sectors. However, this collaborative effort will only work with sustained support from commissioners and providers. By recognising and addressing the 
current problems in the system as a collaborative effort, progress towards a more efficient and person-centred healthcare system becomes possible. The level of change required is profound and we should not be afraid to highlight the scale of the problem and the probable solutions.

Anecdotal evidence is beginning to suggest that the process is influencing practice. However, working in this way is not without its challenges, and we are a long way off from the development of a linked data set locally or across the region that will allow us to assess impact innovations from a cost perspective. Trust is dependent on the exchange of services and interactions and this takes time to establish. We are beginning to see data flow and hope that this will continue in a constantly changing and open system.

At this stage, we need to acknowledge our state of uncertainty about which approaches to P3C are effective, whether it is possible to facilitate a sustained cultural change towards person-centred practice or whether this is context dependent. We are also currently unsure about whether the transactional costs required for coordinated care can be recouped by reductions in service costs and whether we can start to collect adequate data on the experience of care through everyday practice. It will be several years before we have enough data to bring together local evaluations and health economy metrics and dashboards for stakeholders and researchers to draw conclusions about what is effective.

\section{Conclusions}

The current pressures on health and social care systems, with the expectations to deliver more efficient and personcentred models of care, now require a new modus operandi. We are developing and testing an approach based on collaborative action where research and innovative practice are brought together as partners to reduce uncertainty and provide timely practical knowledge and evidence to support those at the coalface delivering new models of P3C.

\section{Abbreviations}

P3C: person-centred coordinated care; SW CLAHRC: South West Peninsula Collaboration for Leadership in Applied Health Research and Care

\section{Acknowledgements \\ This research was supported by the National Institute for Health Research (NIHR) Collaboration for Leadership in Applied Health Research and Care South West Peninsula at the Royal Devon and Exeter NHS Foundation Trust. TS's current post at the University of Oxford is funded by the NIHR Collaboration for Leadership in Applied Health Research and Care Oxford at Oxford Health NHS Foundation Trust. The views expressed are those of the authors and not necessarily those of the NHS, the NIHR or the Department of Health. This research was also funded by the South West Academic health Science Network (AHSN). The views expressed are those of the authors and not necessarily those of the AHSN.}

\section{Funding}

The NIHR CLAHRC Programme fund the substantive posts of HML, RB, NB, HW, TPS and MP as members of the South West Peninsula CLARHC. All other co-authors are members of the wider collaboration and are substantially employed by their respective organisations.
Availability of data and materials

Data sharing is not applicable as no datasets were generated or analysed to produce this paper.

\section{Authors' contributions}

All authors commented on and edited drafts of the manuscripts. HL was the lead author and with RB conceived of the idea of the manuscript. HL and $\mathrm{RB}$ are leading the programme of work detailed in the manuscript. RS, $T S, S A, N B, J V, M P, H L, L W, M B$ and $R B$ are all involved in the work of the programme at a strategic level across Plymouth and Exeter Universities (as part of South West Peninsula (LARHC), SWAHSN and Somerset and South Devon and Torbay Clinical Commissioning Groups. JH, HW and TS contributed to the programme of work. All authors read and approved the final manuscript.

Ethics approval and consent to participate

Not applicable.

\section{Consent for publication}

Not applicable.

\section{Competing interests}

The authors declare that they have no competing interests.

\section{Publisher's Note}

Springer Nature remains neutral with regard to jurisdictional claims in published maps and institutional affiliations.

\section{Author details}

${ }^{1}$ Community and Primary Care Research Group, Clinical Trails and Population Studies, Peninsula School of Medicine and Dentistry, Room N14, ITTC Building, Plymouth Science Park, Derriford, Plymouth, Devon PL6 8BX, United Kingdom. ${ }^{2}$ School of Law, Criminology and Government, University of Plymouth, Portland Villas, Plymouth, Devon PL4 8AA, United Kingdom. ${ }^{3} \mathrm{NIHR}$ CLAHRC South West Peninsula (PenCLAHRC), Institute of Health Research, University of Exeter Medical School, St Luke's Campus, Heavitree Road, Exeter EX1 2LU, United Kingdom. ${ }^{4}$ Health Services \& Policy Research, University of Exeter Collaboration for Academic Primary Care, APEx, University of Exeter Medical School, St Luke's Campus, Heavitree Road, Exeter EX1 2LU, United Kingdom. ${ }^{5}$ Primary Care Development Somerset Clinical Commissioning Group, Working Together to Improve Health and Wellbeing, Wynford House, Lufton Way, Yeovil, Somerset BA22 8HR, United Kingdom. ${ }^{6}$ South West Academic Health Science Network, Pynes Hill Court, Pynes Hill, Exeter EX2 $5 A Z$, United Kingdom.

Received: 10 March 2017 Accepted: 26 October 2017

Published online: 22 November 2017

\section{References}

1. Ryan J, Abrams MK, Doty MM, Shah T, Schneider EC. How high-need patients experience health care in the United States: findings from the 2016 Commonwealth Fund Survey of High-Need Patients. New York, NY: The Commonwealth Fund; 2016

2. Curry N, Goodwin N, Naylor C, Robinson R. Practice based commissioning. Reinvigorate, replace or abandon? London: Kings Fund; 2008.

3. Sheaff RHJ, Øvretveit J, Byng R, Exworthy M, Peckham S, et al. Integration and continuity of primary care: polyclinics and alternatives, an organisational analysis. Health Serv Deliv Res. 2015;3:35. doi:10.3310/ hsdr03350.

4. National Voices. A Narrative for Person Centred Coordinated Care. 2013. https://www.nationalvoices.org.uk/publications/our-publications/narrativeperson-centred-coordinated-care.

5. Royal College of Physicians. Putting the Pieces Together: Removing the Barriers to Excellent Patient Care. London: Royal College of Physicians; 2015.

6. Humphries R. Health and social care for older people: progress, problems and priorities. Qual Ageing Older Adults. 2015;16(1):27-31.

7. Schoen C, Osborn R, Squires D, Doty M, Pierson R, Applebaum S. New 2011 survey of patients with complex care needs in eleven countries finds that care is often poorly coordinated. Health Affairs (Project Hope). 2011;30(12):2437.

8. Oliver D, Foot C, Humphries R. Making our Health and Care Systems Fit for an Ageing Population. London: The Kings Fund; 2014. 
9. Barnett K, Mercer SW, Norbury M, Watt G, Wyke S, Guthrie B. Epidemiology of multimorbidity and implications for health care, research, and medical education: a cross-sectional study. Lancet. 2012;380(9836):37-43.

10. Goodwin N, Smith J, Davies A, Perry C, Rosen R, Dixon A, et al. Integrated Care for Patients and Populations: Improving Outcomes by Working Together. London: The King's Fund and the Nuffield Trust; 2012.

11. Kupeli N, Leavey G, Harrington J, Lord K, King M, Nazareth I, et al. What are the Barriers to Care Integration for those at the Advanced Stages of Dementia Living in Care Homes in the UK? Health Care Professional Perspective. London: Dementia; 2016.

12. Walsh B, Addington-Hall J, Roberts HC, Nicholls PG, Corner J. Outcomes after unplanned admission to hospital in older people: ill-defined conditions as potential indicators of the frailty trajectory. J Am Geriatr Soc. 2012;60(11):2104-9.

13. Kasteridis P, Street A, Dolman M, Gallier L, Hudson K, Martin J, et al. Who would most benefit from improved integrated care? Implementing an analytical strategy in South Somerset. Int J Integr Care. 2015:15:e001.

14. Bock J-O, Konig H-H, Brenner $H$, Haefeli WE, Quinzler R, Matschinger $H$, et al. Associations of frailty with health care costs - results of the ESTHER cohort study. BMC Health Serv Res. 2016;16:127.

15. Tian $Y$, Thompson J, Buck D. The cost of falls: exploring the cost of the whole system pathway for older people in a rural community in England. J Integr Care. 2014;22(4):173-65.

16. Sinnott C, Mc Hugh S, Browne J, Bradley C. GPs' perspectives on the management of patients with multimorbidity: systematic review and synthesis of qualitative research. BMJ Open. 2013;3(9):e003610.

17. Baird BC, Charles A, Honeyman M, Maguire D, Das P. Understanding Pressures in General Practice. London: The Kings Fund; 2016.

18. Ham C. World Class Commissioning: a health policy chimera? J Health Serv Res Policy. 2008;13(2):116-21.

19. Armitage GD, Suter E, Oelke ND, Adair CE. Health systems integration: state of the evidence. Int J Integr Care. 2009;9:e82.

20. Kane RL. Strategies for improving chronic illness care: some issues for the NHS. Aging Health. 2007;3(3):333-42.

21. Beswick AD, Rees K, Dieppe P, Ayis S, Gooberman-Hill R, Horwood J, et al. Complex interventions to improve physical function and maintain independent living in elderly people: a systematic review and meta-analysis. Lancet. 2008:371(9614):725-35.

22. Helen F, Sally H, John F. Interventions in community settings that prevent or delay disablement in later life: an overview of the evidence. Qual Ageing Older Adults. 2012;13(3):212-30

23. Pearson M, Sheaff R, Valderas-Martinez J, Byng R, Lloyd H, Brand S. From Programme Theory to Logic Models for Multi-Specialty Community Providers: A Realist Evidence Synthesis. National Institute for Health Research. 2017. http://clahrc-peninsula.nihr.ac.uk/research/from-programmetheory-to-logic-models-for-multispecialty-community-providers-a-realistevidence-synthesis. Accessed 1 Nov 2017.

24. Sheaff R, Halliday J, Ovretveit J, Byng R, Exworthy M, Peckham S, et al. Integration and continuity of primary care: polyclinics and alternatives - a patient-centred analysis of how organisation constrains care co-ordination. Health Serv Deliv Res. 2015;3(35):201.

25. Dennis K. All together now: a conceptual exploration of integrated care. Healthcare Quarterly. 2009;13(Sp):6-15.

26. Erens B, Wistow G, Mounier-Jack S, Douglas N, Jones L, Manacorda T, Mays N. Early Evaluation of the Integrated Care and Support Pioneers Programme. Final Report. Policy Innovation Research Unit (PIRU). Department of Health Services Research \& Policy, London School of Hygiene and Tropical Medicine. 2016. www.piru.ac.uk/assets/files/Early_ evaluation_of_IC_Pioneers_Final_Report.pdf. Accessed 1 Nov 2017.

27. Leutz WN. 'Five Laws for Integrating Medical and Social Services: Lessons from the United States and the United Kingdom'. Milbank Q. 1999;77(1):77

28. Jarzabkowski P, Sillince JA, Shaw D. Strategic ambiguity as a rhetorical resource for enabling multiple interests. Hum Relations. 2010;63(2):219-48.

29. Matland RE. Synthesizing the implementation literature: the ambiguity-conflict model of policy implementation. J Public Adm Res Theory. 1995;5(2):145-74.

30. Ring PS, Perry JL. Strategic management in public and private organizations: implications of distinctive contexts and constraints. Acad Manag Rev. 1985;10(2):276-86

31. Noel PH, Frueh BC, Larme AC, Pugh JA. Collaborative care needs and preferences of primary care patients with multimorbidity. Health Expect. 2005;8(1):54-63.
32. Duguay C, Gallagher F, Fortin M. The experience of adults with multimorbidity: a qualitative study. J Comorbidity. 2014;4:11-21.

33. Wallace E, Salisbury C, Guthrie B, Lewis C, Fahey T, Smith SM. Managing patients with multimorbidity in primary care. BMJ. 2015;350:h176.

34. Mercer SW, Gunn J, Bower P, Wyke S, Guthrie B. Managing patients with mental and physical multimorbidity. BMJ. 2012;345:e5559.

35. Loffler C, Kaduszkiewicz H, Stolzenbach CO, Streich W, Fuchs A, van den Bussche $\mathrm{H}$, et al. Coping with multimorbidity in old age-a qualitative study. BMC Fam Pract. 2012;13:45.

36. Smith SM, Soubhi H, Fortin M, Hudon C, O'Dowd T. Managing patients with multimorbidity: systematic review of interventions in primary care and community settings. BMJ. 2012;345:e5205.

37. France EF, Wyke S, Gunn JM, Mair FS, McLean G, Mercer SW. Multimorbidity in primary care: a systematic review of prospective cohort studies. Br J Gen Pract. 2012;62(597):e297-307.

38. NHS England. The General Practice Forward View. 2016. https://www.england. nhs.uk/wp-content/uploads/2016/04/gpfv.pdf. Accessed 1 Nov 2017.

39. NHS England. The Five Year Forward View. 2014. https://www.england.nhs. uk/wp-content/uploads/2014/10/5yfv-web.pdf. Accessed 1 Nov 2017.

40. Gravelle H, Dusheiko M, Sheaff R, Sargent P, Boaden R, Pickard S, et al. Impact of case management (Evercare) on frail elderly patients: controlled before and after analysis of quantitative outcome data. BMJ. 2007:334(7583):31.

41. Horrell JL, H., Sugavanam, T., Close, J., Byng, R. Creating and Facilitating Change for Person Centred Coordinated Care (P3C): The Development of the Organisational Change Tool (P3C-OCT). 2017. http://blogs.plymouth.ac. uk/communityandprimarycare/2017/10/11/creating-and-facilitating-changefor-person-centred-coordinated-care-the-organisational-change-tool-janehorrell-and-helen-lloyd/. Accessed 1 Nov 2017.

42. Gilburt H. Supporting Integration through New Roles and Working Across Boundaries. London: Kings Fund; 2016.

43. Auerbach $A D$, Landefeld CS, Shojania KG. The tension between needing to improve care and knowing how to do it. N Engl J Med. 2007;357(6):608-13.

44. Pawson R, Tilley N. Realistic Evaluation. London: SAGE Publications; 1997.

45. Rycroft-Malone J, Wilkinson J, Burton CR, Harvey G, McCormack B, Graham I, et al. Collaborative action around implementation in Collaborations for Leadership in Applied Health Research and Care: towards a programme theory. J Health Serv Res Policy. 2013;18(3 Suppl):13-26.

46. Glasgow RE, Green LW, Taylor MV, Stange KC. An evidence integration triangle for aligning science with policy and practice. Am J Prev Med. 2012;42(6):646-54

47. NHS England. Integrated Personal Commissioning (IPC). 2017. https://www. england.nhs.uk/ipc/. Accessed 1 Nov 2017.

48. NHS England. Vanguards. 2017. https://www.england.nhs.uk/ourwork/newcare-models/vanguards/. Accessed 1 Nov 2017.

49. NHS England. Realising the Value. NHS England Launches Initiative to Empower Patients and Communities to take Control of their Health. 2014. https://www.england.nhs.uk/2014/11/realising-value/. Accessed 2 June 2016.

50. Lloyd H, Sugavanam, T, Wheat H, Horrell J, Close J. A Guide for Commissioners on the Use Metrics for Person Centred Cooridnated Care for People with Long Term Conditions, Multiple Long Term Conditions and Those at the End of their Life. London: National Health Service England; 2017.

51. Sugavanam T, Byng R, Horrell J, Fosh B, Close J, Lloyd H. Co-designing a generic measure to probe person centred coordinated care from the perspective of the patient: the development of the P3CEQ. J Patient Experience. 2017. Ahead of print.

52. Green LW. Making research relevant: if it is an evidence-based practice, where's the practice-based evidence? Fam Pract. 2008:25 Suppl 1:i20-4.

53. Dow B. Development and initial testing of the Person-Centred Health Care for Older Adults Survey. Int Psychogeriatr. 2013;25:1065-76.

54. Hibbard JH, Stockard J, Mahoney ER, Tusler M. Development of the Patient Activation Measure (PAM): conceptualizing and measuring activation in patients and consumers. Health Serv Res. 2004;39(4 Pt 1):1005-26.

55. Tennant R, Hiller L, Fishwick R, Platt S, Joseph S, Weich S, et al. The WarwickEdinburgh Mental Well-being Scale (WEMWBS): development and UK validation. Health Qual Life Outcomes. 2007:5:63.

56. Pawson R. The Science of Evaluation: A Realist Manifesto. London: Sage; 2013.

57. Pearson M, Brand SL, Quinn C, Shaw J, Maguire M, Michie S, Briscoe S, Lennox C, Stirzaker A, Kirkpatrick T, Byng R. Using realist review to inform intervention development: methodological illustration and conceptual 
platform for collaborative care in offender mental health. Implement Sci. 2015;10:134.

58. The King's Fund. http://www.kingsfund.org.uk/blog/2014/11/power-people. Accessed 1 Nov 2017.

59. Health Foundation. http://www.health.org.uk/theme/person-centred-care. Accessed 1 Nov 2017

60. Moore Foundation. http://patientfamilyengagement.org/. Accessed 1 Nov 2017.

61. Richards T. Listen to patients first. BMJ. 2014;349:g5765.

62. Public Health England \& National Health Service England. A Guide to Community-Centred Approaches for Health and Wellbeing. Full Report. London: Public Health England; 2015.

63. Agency for Health Care Research and Quality (AHRQ). Care Coordination Measures Atlas. http://www.ahrq.gov/professionals/prevention-chroniccare/improve/coordination/atlas2014/chapter2.html. Accessed 1 Nov 2017.

Submit your next manuscript to BioMed Central and we will help you at every step:

- We accept pre-submission inquiries

- Our selector tool helps you to find the most relevant journal

- We provide round the clock customer support

- Convenient online submission

- Thorough peer review

- Inclusion in PubMed and all major indexing services

- Maximum visibility for your research

Submit your manuscript at www.biomedcentral.com/submit
Biomed Central 